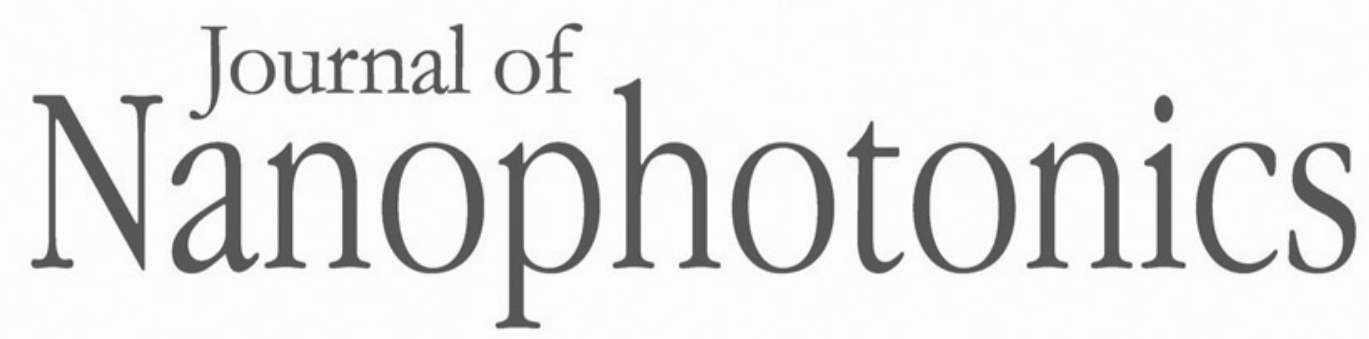

Nanophotonics.SPIEDigitalLibrary.org

\title{
Special Section Guest Editorial: Nanoscience and Biomaterials in Photonics
}

\author{
James G. Grote \\ Bert Müller
}




\title{
Special Section Guest Editorial: Nanoscience and Biomaterials in Photonics
}

\author{
James G. Grote ${ }^{a}$ and Bert Müller ${ }^{b}$ \\ ${ }^{a}$ Air Force Research Laboratory, Materials and Manufacturing Directorate, \\ Dayton, Ohio, United States \\ ${ }^{b}$ Biomaterials Science Center, Department of Biomedical Engineering, \\ University of Basel, 4123 Allschwil, Switzerland
}

Being involved with the field of nanoscience and engineering over the years, both from a research perspective and from our involvement with SPIE conferences, we have seen that nanometer-scale physics initiated revolutionary advances in the development of original analytical tools, functional nanomaterial combinations and devices, as well as multidisciplinary approaches to materials science and engineering, which even reached the pioneering medical treatments of the twenty-first century. In the last few years, we have observed the emergence, and increased presence, of bioinspired and biomimetic materials, processes, and devices in research reflected in expanding conference participation. We see life sciences, often abbreviated by bio, as a vital area in current nanometer-scale research activities all over the world that have broadened the horizon of nanoscience and nanotechnology. Therefore, nano-bio-technology has had a major impact on electronics and photonics applications, opening up a whole extra field for innovative bioengineering. Highlighted in this special section of JNP you will find a few of the most recent works in this exciting field usually just abbreviated by the prefixes nano- and bio-. A characteristic example are nanometer-thin compliant conductors as introduced by B. Osmani et al., which are required for battery-driven dielectric elastomer transducer-based artificial muscles, for example to treat severe incontinence, for flexible electronics, and truly soft electrodes for deep brain stimulation, just to mention a few. Consequently, we are aware that nano-bio-technology has been changing our everyday life.

\section{Acknowledgments}

The guest editors thank the authors for their contributions to this special section of the journal and also thank the reviewers and editorial staff members who helped put this work together.

James G. Grote is an adjunct professor and researcher at the University of Dayton, teaching and directing research in polymer and biopolymer-based optoelectronics and electronics. He is an Air Force Laboratory Fellow, a Fellow of SPIE, OSA, and the European Optical Society (EOS), a Senior Member of IEEE Photonics Society and a Doctor Honoris Causa, Universitatea Politehnica Din Bucuresti, Romania. He has co-authored 230+ publications, plus two books, seven book chapters and six patents. He has served as editor for more than 25 conference proceedings and journal publications. He has presented over 120 papers and seminars, many of which have been keynote or invited. He has served as chair for numerous international symposiums. He is the current track chair for the nanoengineering track of the SPIE Nano Science and Engineering Symposium.

Bert Müller holds the Thomas Straumann-Chair for Materials Science in Medicine at the University of Basel, Switzerland. His current research interests include high-resolution hard x-ray imaging, nanometer-size mechano-responsive liposomes for targeted drug delivery, applying physics in dentistry, nanotechnology-based artificial muscles for incontinence treatments, nanostructuring of medical implant surfaces, and the next-generation treatment of neurodegenerative diseases. He has been recently elected as a Fellow of SPIE and is an active member of the European Academy of Sciences and Arts. Since 2001, he has been teaching in the Physics Department of ETH Zurich, Switzerland. Currently, he serves as an associate editor for the Journal of Nanophotonics and as a member of the selection committee of SPIE Fellows. 